\title{
Serum cystatin C, impaired kidney function, and geriatric depressive symptoms among older people living in a rural area: a population-based study
}

Ling $\mathrm{Wu}^{1,2}$, Zhongrui Yan ${ }^{2 *}$ (D) Hui Jiang ${ }^{3}$, Huaimei Xing ${ }^{1,2}$, Haohao $\mathrm{Li}^{1,2}$ and Chengxuan $\mathrm{Qiu}^{4,5^{*}}$

\begin{abstract}
Background: The relationship between kidney function and depressive symptoms among elderly people has been rarely investigated in settings of the general population. The aim of our study was to examine the association of serum cystatin $C($ cysC) and impaired kidney function with geriatric depressive symptoms among older people living in a rural community in China.

Methods: This population-based cohort study included 1440 individuals (age $\geq 60$ years) who were recruited for the Confucius Hometown Aging Project in 2010-2011; of the 1124 persons who were free of depressive symptoms, 669 (59.5\%) were re-examined in 2014-2016. At baseline, data on demographics, lifestyle factors, health conditions, and medical history were collected through interviews, clinical examinations, and laboratory tests. We defined impaired kidney function as the cystatin C-based estimated glomerular filtration rate (eGFR cysc) $<60 \mathrm{ml} / \mathrm{min} / 1$. $73 \mathrm{~m}^{2}$, and depressive symptoms as a score $\geq 5$ on the 15-item Geriatric Depression Scale. Data were analyzed using multiple logistic and Cox proportional-hazards models.

Results: Of the 1440 participants, 316 (21.9\%) were defined to have geriatric depressive symptoms at baseline. Serum cysC levels of 1.01-1.25 and $>1.25 \mathrm{mg} / \mathrm{L}$ (vs. $\leq 1.00 \mathrm{mg} / \mathrm{L}$ ) were associated with a multiple-adjusted odds ratio (OR) of 1.41 (95\% Cl 1.01-1.97) and 3.20 (2.32-4.41), respectively, for having geriatric depressive symptoms $\left(P_{\text {trend }}<0.001\right.$ ). Of the 669 people who were free of depressive symptoms at baseline, 157 had incident depressive symptoms at the follow-up examination. The multiple-adjusted hazard ratio (HR) for incident depressive symptoms were 2.16 (95\% Cl 1.43-3.27) for serum cysC > 1.25 mg/L (vs. < $1.00 \mathrm{mg} / \mathrm{L}$ ). Impaired kidney function was crosssectionally (multiple-adjusted $\mathrm{OR}=2.95 ; 95 \% \mathrm{Cl} 2.22-3.92$ ) and longitudinally (multiple-adjusted $\mathrm{HR} 1.54 ; 95 \% \mathrm{Cl} 1$. 03-2.30) associated with an increased risk of geriatric depressive symptoms.
\end{abstract}

Conclusion: Elevated serum cysC levels and impaired kidney function are associated with an increased risk of geriatric depressive symptoms among Chinese older people living in a rural community.

Keywords: Aging, Cystatin C, Kidney function, Depressive symptoms, Cohort study, China

\footnotetext{
* Correspondence: zhongruiy@163.com; chengxuan.qiu@ki.se

${ }^{2}$ Department of Neurology, Jining No. 1 People's Hospital, Jiankang Road 6,

Jining 272111, Shandong, China

${ }^{4}$ Department of Neurology, Shandong Provincial Hospital, Jinan, Shandong,

China

Full list of author information is available at the end of the article
}

(c) The Author(s). 2018 Open Access This article is distributed under the terms of the Creative Commons Attribution 4.0 International License (http://creativecommons.org/licenses/by/4.0/), which permits unrestricted use, distribution, and reproduction in any medium, provided you give appropriate credit to the original author(s) and the source, provide a link to the Creative Commons license, and indicate if changes were made. The Creative Commons Public Domain Dedication waiver (http://creativecommons.org/publicdomain/zero/1.0/) applies to the data made available in this article, unless otherwise stated. 


\section{Background}

As population ages, geriatric depression has become a public health concern. Depression in older people is related not only to poor health-related quality of life [1], but also to morbidity, mortality, and even suicide [2]. The Global Burden of Disease 2010 study identified that depressive disorder was a leading cause of years lived with disability (YLDs), and that major depressive disorder accounted for $8.2 \%$ of global YLDs [3]. In China, the meta-analyses showed that the prevalence of depression ranges from $\sim 20 \%$ to $\sim 30 \%$ among older adults living in communities, with the pooled prevalence being $23 \%[4,5]$. However, depression has been both underdiagnosed and undertreated in primary care settings owing to common co-occurrence with other geriatric conditions in older adults [6]. Therefore, it is particularly important to identify risk factors related to geriatric depression for possible intervention.

Chronic kidney disease or decreased renal function is increasingly common as people age [7]. In US, chronic kidney disease, defined as an estimated glomerular filtration rate $(\mathrm{eGFR})<60 \mathrm{~mL} / \mathrm{min} / 1.73 \mathrm{~m}^{2}$, affected nearly one-third of community-dwelling adults aged over 70 years [8]. However, only a few population-based studies have so far examined the relationship between kidney function and depression in older adults, with mixed results. For instance, a cross-sectional study of Chinese older people aged 70-84 years indicated that eGFR < $60 \mathrm{~mL} / \mathrm{min} / 1.73 \mathrm{~m}^{2}$ was associated with depressive symptoms [9], whereas the Singapore Longitudinal Aging Study found no association between the serum creatinine-based eGFR and depressive symptoms (defined as the 15-item Geriatric Depression Scale [GDS-15] score $\geq 5$ ) [10], and the cross-sectional survey of people over 60 years of age with diabetes in US suggested that only very low eGFR $\left(<29 \mathrm{~mL} / \mathrm{min} / 1.73 \mathrm{~m}^{2}\right)$ was associated with an increased risk of depressive symptoms [11]. However, the population-based longitudinal studies of the relationship between measures of kidney function and geriatric depressive symptoms in older adults are still lacking, especially among Chinese elderly people living in rural areas.

Therefore, we hypothesize that increased serum cystatin $\mathrm{C}$ or impaired kidney function is associated with an increased risk of geriatric depressive symptoms in older people. We sought to test this hypothesis in this population-based cohort study of older adults who were living in a rural community in China.

\section{Methods}

\section{Study participants}

This is a population-based cohort study. Study participants were derived from the Confucius Hometown Aging Project (CHAP), as fully described elsewhere [12].
Briefly, CHAP was aimed at exploring the role of cardiovascular risk factors and atherosclerotic mechanisms in aging and health. In the current study, we sought to specifically examine the associations of baseline serum cysC levels and impaired kidney function with depressive symptoms both at the baseline (cross-sectional association) and the follow-up (longitudinal association) examinations. At baseline (2010-2011), 1440 (82.6\%) of the 1743 eligible participants who were aged $\geq 60$ years and were living in the Xing Long Zhuang community nearby Qufu city (the hometown of Confucius) in Shandong, China were examined for CHAP; of these, 316 persons were defined to have depressive symptoms (GDS-15 score $\geq 5$ ). In 2014-2016, we carried out the second wave of assessment in the same community for residents who were aged $\geq 60$ years in June 2014, following a procedure similar to that of the baseline survey. In total, 669 (59.5\%) of the 1124 persons who were free of depressive symptoms at baseline underwent the follow-up examination. Figure 1 shows the flowchart of the study participants from baseline to the follow-up assessments.

Data collection for all phases of the CHAP study was approved by the Ethics Committee at the Jining No. 1 People's Hospital of Jining Medical University, Shandong, China. Written informed consent was obtained from all participants, or in the case of cognitively impaired persons, from a proxy (usually next-of-kin).

\section{Data collection and definition}

At baseline, data were collected by trained physicians through face-to-face interviews, clinical examination, and laboratory tests, as previously described [12]. We collected data on demographics, lifestyle factors (e.g. smoking and alcohol consumption), health conditions and health history (e.g. hypertension, diabetes, heart disease, stroke, cataract, chronic obstructive pulmonary disease (COPD), arthritis, nephritis, and tumor), and use of medications (e.g., antihypertensive agents and blood glucose-lowering drugs) following a structured questionnaire. Arterial blood pressure was measured twice in the sitting position after resting for at least $5 \mathrm{~min}$, and the mean value of the two measurements was used for analysis. Peripheral blood samples were taken after an overnight fast, and fasting plasma glucose (FPG), serum cystatin C (cysC), high-density lipoprotein (HDL), low-density lipoprotein (LDL), and creatinine were analyzed using the enzymatic methods by an Automatic Biochemistry Analyzer (Olympus AU-400, Japan).

Body mass index (BMI) was calculated as the measured body weight in kilograms divided by the square of height in meters $\left(\mathrm{kg} / \mathrm{m}^{2}\right)$. Smoking status was divided into never and ever (current or former) smoking. Alcohol consumption was assessed based on the frequency 


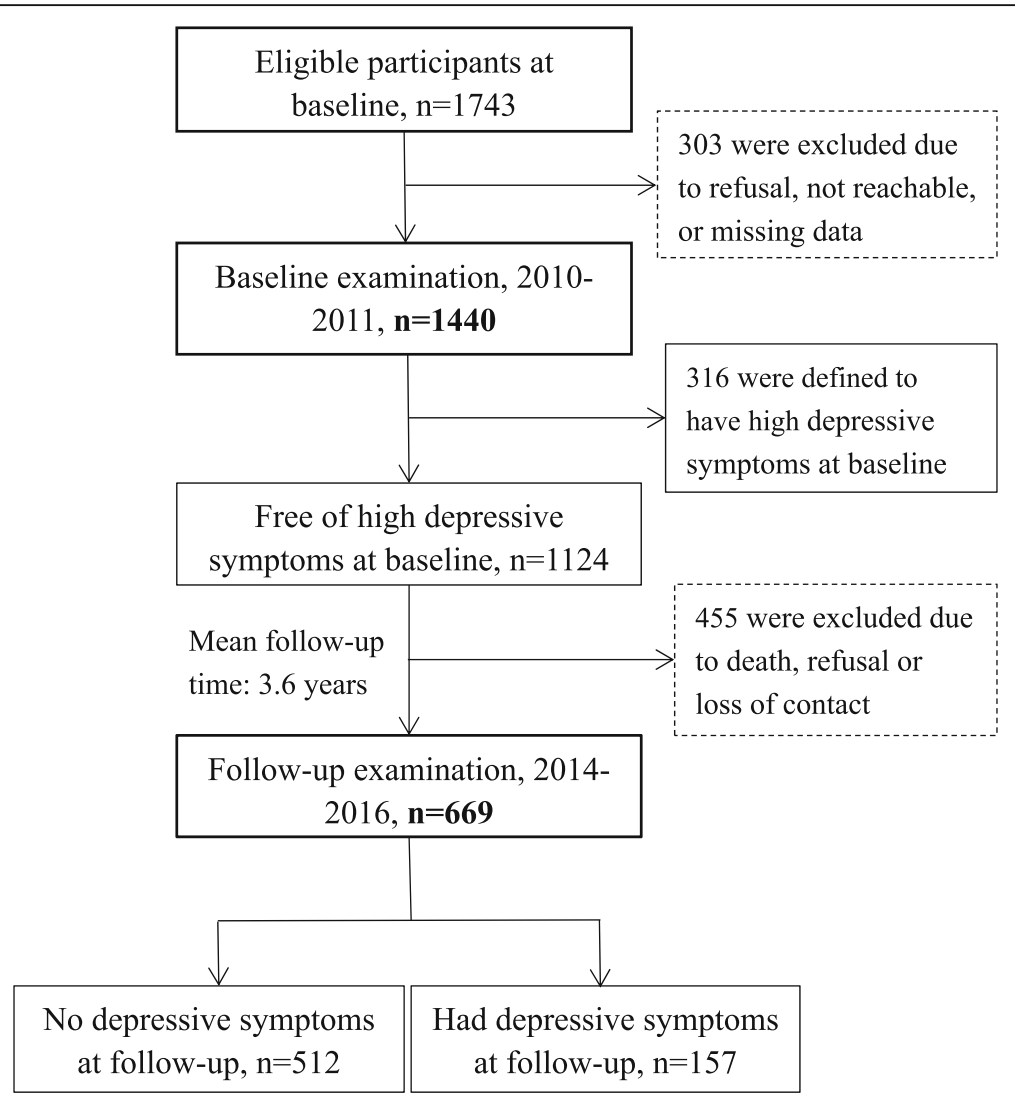

Fig. 1 Flowchart of the study participants, 2010-2011 to 2014-2016

and amount of alcohol intake in a typical day and was dichotomized into yes vs. no. Hypertension was defined as blood pressure $\geq 140 / 90 \mathrm{mmHg}$ or currently using antihypertensive drugs [13]. Diabetes was defined as having a self-reported history of physician's diagnosis of diabetes, FPG $\geq 7.0 \mathrm{mmol} / \mathrm{L}$ or current use of hypoglycemic agents or insulin injection [14]. Heart disease, stroke, cataract, COPD, nephritis, and tumor were ascertained through clinical examination, electrocardiogram test, or self-reported physician's diagnosis or currently taking relevant medications.

Global cognitive function was assessed using the validated Chinese version of the Mini-Mental State Examination (MMSE) [15]. Cognitive impairment was defined according to the education-based cutoff scores on MMSE [16], i.e., an MMSE score $\leq 17$ for persons without formal schooling, $\leq 20$ for those with $1-6$ years of education, and $\leq 24$ for those with $\geq 7$ years of education. Physical functioning was assessed using the Katz's basic activities of daily living (ADL) [17], which involves six self-care activities of bathing, dressing, toileting, continence, transferring, and self-feeding. Participants who were not able to carry out at least one of the six tasks were considered to have disability in basic ADL.

\section{Kidney function}

We calculated the eGFR according to the following equations based on serum cysC (eGFR cysC [18]: eGFR${ }_{\text {cysC }}=133 \times(\mathrm{cysC} / 0.8)^{-0.499} \times 0.996^{\text {age }}[\times 0.932$ if female $]$ (if cysC $\leq 0.8 \mathrm{mg} / \mathrm{L}) ; \quad$ eGFR cysC $=133 \times(\text { cysC/0.8 })^{-1.328} \times$ $0.996^{\text {age }}[\times 0.932$ if female $]$ (if cysC $>0.8 \mathrm{mg} / \mathrm{L}$ ). Impaired kidney function was defined as eGFR $\mathrm{cysC}_{\mathrm{C}}<60 \mathrm{ml} /$ $\min / 1.73 \mathrm{~m}^{2}$ [19].

\section{Geriatric depressive symptoms}

The GDS-15 tool was used to assess the presence of geriatric depressive symptoms at both baseline and follow-up examinations. We considered depressive symptoms to be present if a GDS- 15 score $\geq 5$, a cut-off that has been widely used for screening depression in older adults, with fairly high sensitivity and specificity (ranging from $\sim 75 \%$ to $\sim 95 \%$ ) when evaluated against the clinical criteria (e.g., DSM-IV criteria) [10, 20-22].

\section{Statistical analysis}

Baseline characteristics of study participants by having depressive symptoms at baseline were compared using $t$ test for continuous variables and $\chi^{2}$ test for categorical variables. We categorized the serum cysC level into $\leq 1.0$, 1.01-1.25, and $>1.25 \mathrm{mg} / \mathrm{L}$ [23]. We examined both 
cross-sectional and longitudinal associations of serum cysC and impaired kidney function with geriatric depressive symptoms. For the cross-sectional association, we used multiple logistic regression model to estimate the odds ratio (OR) and 95\% confidence interval (CI) of having geriatric depressive symptoms associated with baseline serum cysC levels and impaired kidney function. To explore the longitudinal association, Cox proportional-hazards models were constructed in participants who were free of depressive symptoms at baseline to estimate the hazard ratio (HR) and 95\% CI of having depressive symptoms at the follow-up associated with serum cysC levels and impaired kidney function at baseline. In the Cox models, the follow-up time from the date of baseline assessment to the date of follow-up examination was used as the time scale. For both cross-sectional and longitudinal associations, we reported results from three models, in which we controlled for different factors that potentially confounded the examined associations: model 1 was controlled for age, gender, and education (in years); model 2 was additionally controlled for alcohol consumption and history of chronic diseases (e.g. hypertension, heart disease, stroke, cataract, nephritis, arthritis, COPD); and model 3 was further controlled for MMSE score and ADL-disability. We considered $p<0.05$ $(\alpha)$ for a two-tailed test to be statistically significant. IBM SPSS Statistics 19.0 for Windows (Armonk, NY: IBM Corp.) was used for all analyses.

\section{Results}

At baseline, the mean age of the 1440 participants was 68.5 years (SD, 4.9), and $60 \%$ were women. Of them, 316 had geriatric depressive symptoms, which resulted in the overall prevalence of $21.9 \%$, with the prevalence being higher in women than in men $(24.8 \%$ vs. $17.7 \%, p=$ 0.002). Compared with people without geriatric depressive symptoms, those with depressive symptoms were older and had a higher prevalence of chronic health conditions (e.g., hypertension, heart disease, stroke, COPD, cataract, arthritis, and ADL-disability) (Table 1). Furthermore, people with depressive symptoms had a higher level of LDL, serum cysC, and creatinine, but a lower level of $\mathrm{HDL}, \mathrm{GFR}_{\mathrm{cysC}}$, and MMSE score than those

Table 1 Baseline characteristics of study participants according to depressive symptoms at baseline

\begin{tabular}{|c|c|c|c|c|}
\hline \multirow[t]{2}{*}{ Characteristics } & \multirow{2}{*}{$\begin{array}{l}\text { Total sample } \\
(n=1440)\end{array}$} & \multicolumn{3}{|c|}{ Depressive symptoms } \\
\hline & & No $(n=1124)$ & Yes $(n=316)$ & $p$-value \\
\hline Female, n (\%) & $864(60.0)$ & $650(75.2)$ & $214(24.8)$ & 0.002 \\
\hline Age (years), mean (SD) & $68.5(4.9)$ & $68.3(4.9)$ & $69.4(5.1)$ & 0.001 \\
\hline Education (years), mean (SD) & $3.9(3.4)$ & $4.0(3.4)$ & $3.7(3.3)$ & 0.180 \\
\hline BMI $\left(\mathrm{kg} / \mathrm{m}^{2}\right)$, mean $(\mathrm{SD})$ & $26.4(8.1)$ & $26.5(8.9)$ & $26.2(4.2)$ & 0.599 \\
\hline Current smoking ${ }^{\mathrm{a}}, \mathrm{n}(\%)$ & $206(14.3)$ & $162(14.4)$ & $44(13.9)$ & 0.970 \\
\hline Alcohol consumption ${ }^{\mathrm{a}}, \mathrm{n}(\%)$ & $299(20.8)$ & $247(22.0)$ & $52(16.5)$ & 0.018 \\
\hline Hypertension, n (\%) & $768(53.3)$ & $573(51.0)$ & $195(61.7)$ & 0.001 \\
\hline Diabetes, n (\%) & $322(22.4)$ & $246(21.9)$ & $76(24.1)$ & 0.415 \\
\hline Heart disease $^{a}, \mathrm{n}(\%)$ & $486(33.8)$ & $357(31.8)$ & $129(40.8)$ & 0.009 \\
\hline Stroke, $\mathrm{n}(\%)$ & $124(8.6)$ & $86(7.7)$ & $38(12.0)$ & 0.044 \\
\hline Cataract, n (\%) & $200(13.9)$ & $145(12.9)$ & $55(17.4)$ & 0.041 \\
\hline $\mathrm{COPD}^{\mathrm{a}}, \mathrm{n}(\%)$ & $199(13.8)$ & $142(12.6)$ & $57(18.0)$ & 0.029 \\
\hline Arthritis $^{\mathrm{a}}, \mathrm{n}(\%)$ & $518(36.0)$ & $384(34.2)$ & $134(42.4)$ & 0.015 \\
\hline Nephritis ${ }^{a}, \mathrm{n}(\%)$ & $69(4.8)$ & $52(4.6)$ & $17(5.4)$ & 0.763 \\
\hline Tumor, n (\%) & $51(3.5)$ & $37(3.3)$ & $14(4.4)$ & 0.333 \\
\hline cysC (mg/L), mean (SD) & $0.99(0.29)$ & $0.97(0.29)$ & $1.09(0.26)$ & $<0.001$ \\
\hline $\mathrm{HDL}(\mathrm{mmol} / \mathrm{L})$, mean (SD) & $1.49(0.44)$ & $1.50(0.42)$ & $1.44(0.49)$ & 0.023 \\
\hline LDL (mmol/L), mean (SD) & $2.69(0.85)$ & $2.67(0.85)$ & $2.78(0.87)$ & 0.045 \\
\hline Creatinine $(\mu \mathrm{mol} / \mathrm{L})$, mean $(\mathrm{SD})$ & $70.5(21.8)$ & $69.7(22.8)$ & $73.3(17.7)$ & 0.010 \\
\hline eGFR (ml/min/1.73 m²), mean (SD) & $81.3(30.6)$ & $84.2(31.7)$ & $71.2(23.4)$ & $<0.001$ \\
\hline MMSE score, mean (SD) & $26.2(4.5)$ & $26.4(4.4)$ & $25.5(4.8)$ & 0.002 \\
\hline ADL-disability, n (\%) & $32(2.2)$ & $12(1.1)$ & $20(6.3)$ & $<0.001$ \\
\hline
\end{tabular}

Abbreviations: $B M I$ body mass index, COPD chronic obstructive pulmonary disease, cysC cystatin $C, H D L$ high-density lipoprotein, $L D L$ low-density lipoprotein, eGFR estimated glomerular filtration rate, MMSE mini-mental state examination, $A D L$ activities of daily living

${ }^{a}$ Numbers of subjects with missing values were 5 for smoking, 11 for alcohol consumption, 1 for stroke, 3 for heart disease, 4 for COPD, 2 for arthritis, and 3 for nephritis. In the subsequent analyses, subjects with missing values were placed in the non-exposure group 
without depressive symptoms. The two groups had no significant difference in educational level, BMI, smoking, diabetes, nephritis, and tumor (Table 1).

For the baseline cross-sectional relationship, compared to people with serum cysC level of $\leq 1.00 \mathrm{mg} / \mathrm{l}$, those with levels of 1.01-1.25 and $>1.25 \mathrm{mg} / \mathrm{l}$ had an increased likelihood of having geriatric depressive symptoms, with the multiple-adjusted OR (95\% CI) being 1.41 (1.01-1.97) and 3.20 (2.32-4.41), respectively ( $p$ for linear trend $<0.001$ ). Impaired kidney function $\left(\mathrm{eGFR}_{\mathrm{cysC}}<60 \mathrm{ml} / \mathrm{min} / 1.73 \mathrm{~m}^{2}\right.$ ) was significantly associated with an increased likelihood of having depressive symptoms (multiple-adjusted $\mathrm{OR}=2.95$; 95\% CI 2.22-3.92) (Table 2).

At an average 3.6 years (SD, 0.62) of follow-up, 157 out of the 669 persons who had no depressive symptoms at baseline were ascertained to have incident geriatric depressive symptoms. People who developed incident depressive symptoms at the follow-up were more likely to be female and to have lower education than those who did not. Cox regression analysis suggested that having an elevated serum cysC level (> 1.25 vs. $<1.00 \mathrm{mg} / \mathrm{L}$ ) was significantly associated with an increased HR of having incident depressive symptoms, even in model 3 when controlling for multiple potential confounders $(\mathrm{HR}=$ 2.16, 95\% CI 1.43-3.27) ( $p$ for linear trend $<0.001$ ) (Table 3). Impaired kidney function at baseline was significantly associated with a $54 \%$ increased risk of incident geriatric depressive symptoms detected at the follow-up assessment (multiple-adjusted HR 1.54; 95\% CI 1.03-2.30) (Table 3).

\section{Discussion}

In this community-based cohort study, we found that geriatric depressive symptoms affected more than one-fifth of Chinese older adults who were living in a rural area. In addition, both the cross-sectional and longitudinal data suggested that higher levels of serum cysC were associated with an increased risk of having geriatric depressive symptoms in a dose-response manner, even after adjusting for multiple potential confounders, including sociodemographic factors, lifestyles, cardiovascular disorders, cognitive function, and physical disability. Finally, impaired kidney function, when assessed based on eGFR $\mathrm{cysC}_{\text {, }}$ was associated with both prevalent and incident geriatric depressive symptoms, independent of multiple confounders. This study suggests that high serum cysC levels and impaired kidney function may be risk factors for depressive symptoms in geriatric populations.

The relationship between renal function and depression among older adults has rarely been explored so far in the general population settings. The cross-sectional data from the Maastricht Study of older adults indicated that albuminuria was associated with incidence of depressive symptoms, whereas the reduced eGFR based on creatinine and cystatin $\mathrm{C}\left(\mathrm{eGFR}_{\mathrm{Cr}-\mathrm{cys}}\right)$ was not associated with minor or major depressive episodes [24]. The follow-up data from the US Health, Aging and Body Composition Study of community-dwelling older adults suggested that an elevated serum cys $C$ level was associated with a 2-fold increased risk of depression, but impaired renal function, assessed based on eGFR $\mathrm{Cr}_{\mathrm{Cr} \text { cysC }}<$ $60 \mathrm{ml} / \mathrm{min} / 1.73 \mathrm{~m}^{2}$, was not related to depression [25]. Of note, some of the previous studies that do not show an association between reduced eGFR and depressive symptoms in older adults have used either serum creatinine or a combination of serum creatinine and cysC to assess eGFR [10, 24, 25]. Because creatinine excretion

Table 2 Cross-sectional associations of serum cystatin C and impaired kidney function with prevalent geriatric depressive symptoms $(n=1440)$

\begin{tabular}{|c|c|c|c|c|}
\hline \multirow{2}{*}{$\begin{array}{l}\text { Serum cystatin C } \\
\text { or impaired kidney } \\
\text { function }\end{array}$} & \multirow[t]{2}{*}{$\mathrm{N} / \mathrm{n}$} & \multicolumn{3}{|c|}{ Odds ratio (95\% confidence interval) } \\
\hline & & Model $1^{\text {a }}$ & Model $2^{\mathrm{a}}$ & Model $3^{\text {a }}$ \\
\hline \multicolumn{5}{|l|}{ Cystatin C, mg/L } \\
\hline$\leq 1.00$ & $768 / 119$ & 1.00 (reference) & 1.00 (reference) & 1.00 (reference) \\
\hline $1.01-1.25$ & $360 / 79$ & $1.43(1.03-1.98)$ & $1.40(1.004-1.95)$ & $1.41(1.009-1.97)$ \\
\hline$>1.25$ & $312 / 118$ & $3.25(2.39-4.42)$ & $3.30(2.40-4.50)$ & $3.20(2.32-4.41)$ \\
\hline$P$ for trend & & $<0.001$ & $<0.001$ & $<0.001$ \\
\hline \multicolumn{5}{|c|}{ Impaired kidney function } \\
\hline No & 1070/176 & 1.00 (reference) & 1.00 (reference) & 1.00 (reference) \\
\hline Yes & $370 / 140$ & $3.07(2.34-4.03)$ & $3.03(2.30-4.01)$ & $2.95(2.22-3.92)$ \\
\hline
\end{tabular}

$\mathrm{N} / \mathrm{n}$ indicates number of subjects/number of persons with depressive symptoms

Abbreviations: MMSE mini-mental state examination, $A D L$ activities of daily living

a Model 1 was adjusted for age, sex, and education; model 2 was additionally adjusted for alcohol consumption, hypertension, stroke, heart disease, cataract, chronic obstructive pulmonary disease, nephritis, and arthritis; and in model 3, MMSE score and ADL-disability were added to model 2 
Table 3 Longitudinal associations of serum cystatin $C$ and impaired kidney function with incident geriatric depressive symptoms $(n=669)$

\begin{tabular}{|c|c|c|c|c|}
\hline \multirow{2}{*}{$\begin{array}{l}\text { Serum cystatin C } \\
\text { or impaired kidney } \\
\text { function }\end{array}$} & \multirow[t]{2}{*}{$N / n$} & \multicolumn{3}{|c|}{ Hazard ratio (95\% confidence interval) } \\
\hline & & Model $1^{\text {a }}$ & Model $2^{\mathrm{a}}$ & Model $3^{\text {a }}$ \\
\hline \multicolumn{5}{|l|}{ Cystatin C, mg/L } \\
\hline$\leq 1.00$ & $388 / 78$ & 1.00 (reference) & 1.00 (reference) & 1.00 (reference) \\
\hline $1.01-1.25$ & $175 / 40$ & $1.11(0.75-1.65)$ & $1.22(0.82-1.81)$ & $1.21(0.81-1.80)$ \\
\hline$>1.25$ & $106 / 39$ & $2.20(1.48-3.27)$ & $2.23(1.48-3.34)$ & $2.16(1.43-3.27)$ \\
\hline$p$ for linear trend & & 0.001 & 0.001 & 0.001 \\
\hline \multicolumn{5}{|c|}{ Impaired kidney function } \\
\hline No & $544 / 122$ & 1.00 (reference) & 1.00 (reference) & 1.00 (reference) \\
\hline Yes & $125 / 35$ & $1.57(1.06-2.32)$ & $1.57(1.05-2.34)$ & $1.54(1.03-2.30)$ \\
\hline
\end{tabular}

$\mathrm{N} / \mathrm{n}$ indicates number of subjects/number of persons with depressive symptoms Abbreviations: MMSE mini-mental state examination, $A D L$ activities of daily living

${ }^{a}$ Model 1 was adjusted for age, sex, and education; model 2 was additionally adjusted for alcohol consumption, hypertension, stroke, heart disease, cataract, chronic obstructive pulmonary disease, nephritis, and arthritis; and in model 3, MMSE score and ADL-disability were added to model 2

is dependent on age, muscle mass, and nutritional status, especially among older adults, serum cysC has been considered to be more accurate and more sensitive in assessing renal function [26, 27]. Indeed, we did not find any association between serum creatinine and depressive symptoms (data not shown). When estimating the eGFR based on serum cysC, we found that reduced $\mathrm{eGFR}_{\mathrm{cys}} \mathrm{C}$ or impaired kidney function was associated both cross-sectionally and longitudinally with an increased risk of having geriatric depressive symptoms among Chinese older adults. This is consistent with a cross-sectional study among Chinese older people (age 70-84 years), in which impaired kidney function was associated with a 1.71-fold increased likelihood of having depressive symptoms (GDS-15 score $\geq 5$ ) [9].

The biological and pathological mechanisms linking serum cysC and impaired kidney function with geriatric depressive symptoms are not fully understood, but multiple pathways are supposed to be involved. First, impaired kidney function or reduced $\mathrm{eGFR}_{\mathrm{cys}}$ due to glomerular small vessel disease has been correlated with subclinical cerebral microvascular disease in older adults $[28,29]$. Further, cerebral microvascular dysfunction and diseases in brain regions involved in mood regulation were associated with late-life depression ("vascular depression") [30, 31]. Thus, impaired kidney function or reduced eGFR might be linked with late-life depressive symptoms through cerebral small vessel disease. Second, serum cysC, as a cysteine protease inhibitor, affects the migration of neutrophils and involves the inflammatory process [32, 33], which may impair function of the brain-serotonin system and stimulate the activation of the hypothalamus-pituitary-adrenal axis to cause depressive symptoms through inflammation pathway [34]. In addition, the population-based studies of older adults have linked inflammatory markers (e.g., C-reactive protein, IL-6, and TNF- $\alpha$ receptor 1 ) with elevated serum cysC or impaired kidney function defined by $\mathrm{eGFR}_{\text {cysC }}$ $[35,36]$. The meta-analysis of population-based studies also supported an association of several inflammatory markers with depression in older adults [37], suggesting the involvement of inflammation in the development of depression. Thus, inflammatory mechanisms may mediate the relationship between serum cys $C$ and depressive symptoms. Of note, our data showed that the association of high serum cysC and impaired kidney function with depressive symptoms was present independent of the inflammation-related diseases such as atherosclerotic disorders, arthritis, and cognitive and functional impairment, suggesting that additional pathways may be involved in linking high serum cysC with geriatric depressive symptoms.

Our cohort study involved both cross-sectional and longitudinal data of older adults who were living in a rural area in China. Moreover, we collected comprehensive data (e.g., demographics, lifestyles, health history, and cognitive and physical functioning) following a standard approach. Thus, we were able to control for a broad range of potential confounding factors. However, our study also has limitations. First, we used GDS-15 to assess geriatric depressive symptoms instead of a clinical diagnosis of depression, although the GDS-15 cut-off score $\geq 5$, as a widely screening instrument for major depressive disorders in older adults, did show high sensitivity and specificity in geriatric populations [10, 21, 22]. Second, we used the cysC-based eGFR as an approximation of glomerular filtration rate instead of a direct measurement, although eGFR has been widely used to define kidney function. Finally, the study population was derived from a single rural community in Eastern China, 
where people had relatively low education and low socioeconomic position. Thus, caution is needed when generalizing our results to other populations.

\section{Conclusion}

This population-based cohort study showed that depressive symptoms were common among Chinese older adults living in a rural community and that high serum cysC levels and impaired kidney function (assessed using serum cysC-based eGFR) were associated with an increased risk of having geriatric depressive symptoms. While our findings warrant further confirmation in other populations, this study suggests that psychological interventions among older adults with impaired kidney function may help reduce the risk of geriatric depression.

\section{Abbreviations}

ADL: Activities of daily living; BMI: Body mass index; CHAP: The Confucius Hometown Aging Project; Cl: Confidence interval; COPD: Chronic obstructive pulmonary disease; CysC: Cystatin C; eGFR cysc: Cystatin C-based estimated glomerular filtration rate; FPG: Fasting plasma glucose; GDS-15: The 15-item Geriatric Depression Scale; HDL: High-density lipoprotein; HR: Hazard ratio; LDL: Low-density lipoprotein; MMSE: Mini-Mental State Examination; OR: Odds ratio

\section{Acknowledgements}

The authors would like to thank all the study participants for their contribution to the Confucius Hometown Aging Project.

\section{Funding}

The Confucius Hometown Aging Project (CHAP) was supported in part by grants from the Department of Science and Technology (2008GG30002058), the Department of Health (2009-067), and the Department of Natural Science Foundation (ZR2010HL031) in Shandong, China and by the Young Scholar Grant for Strategic Research in Epidemiology at Karolinska Institutet, Stockholm, Sweden. Dr. C Qiu received grants from the Swedish Research Council (grants no.: 2017-00740 and 2017-05819), the Swedish Research Council for Health, Working Life and Welfare (grant no.: 2014-01382), Stockholm, Sweden, and the Taishan Scholar Program of Shandong Province, China

\section{Availability of data and materials}

The datasets used and/or analyzed during the current study are available from the corresponding author on reasonable request (Dr Zhongrui Yan, email: zhongruiy@163.com).

\section{Authors' contributions}

LW, ZY, and CQ designed the study. ZY and HJ obtained the data. LW, HX, and $H L$ analyzed the data. $L W$ and $C Q$ drafted the paper. $L W, H X$, and $H L$ had full access to all the data in this study and take responsibility for the integrity of the data and accuracy of the data analysis. ZY and CQ supervised this study. All authors made critical revisions and approved the submission.

\section{Ethics approval and consent to participate}

Data collection for all phases of the Confucius Hometown Aging Project was approved by the Ethics Committee at the Jining No. 1 People's Hospital of Jining Medical University, Shandong, China. Written informed consent was obtained from all participants, or in the case of cognitively impaired persons, from a proxy (usually next-of-kin).

\section{Consent for publication}

Not applicable.

\section{Competing interests}

The authors declare that they have no competing interests.

\section{Publisher's Note}

Springer Nature remains neutral with regard to jurisdictional claims in published maps and institutional affiliations.

\section{Author details}

${ }^{1}$ Cheeloo College of Medicine, Shandong University, Jinan, Shandong, China. 2Department of Neurology, Jining No. 1 People's Hospital, Jiankang Road 6, Jining 272111, Shandong, China. ${ }^{3}$ Xing Long Zhuang Hospital, Shandong Yankuang Group, Jining, Shandong, China. ${ }^{4}$ Department of Neurology, Shandong Provincial Hospital, Jinan, Shandong, China. ${ }^{5}$ Aging Research Center, Department of Neurobiology, Care Sciences and Society, Karolinska Institutet-Stockholm University, Widerströmska Huset, Tomtebodavägen 18A, 17165 Solna, Sweden.

Received: 3 March 2018 Accepted: 18 October 2018

Published online: 06 November 2018

\section{References}

1. Sivertsen H, Bjørkløf GH, Engedal K, Selbæk G, Helvik AS. Depression and quality of life in older persons: a review. Dement Geriatr Cogn Disord. 2015: 40:311-39.

2. Fiske A, Wetherell JL, Gatz M. Depression in older adults. Annu Rev Clin Psychol. 2009;5:363-89.

3. Ferrari AJ, Charlson FJ, Norman RE, Patten SB, Freedman G, Murray CJ, Vos T, Whiteford HA. Burden of depressive disorders by country, sex, age, and year: findings from the global burden of disease study 2010. PLoS Med. 2013;10: e1001547.

4. Li D, Zhang DJ, Shao JJ, Qi XD, Tian L. A meta-analysis of the prevalence of depressive symptoms in Chinese older adults. Arch Gerontol Geriatr. 2014;58:1-9.

5. Zhang $L, X u Y$, Nie $H$, Zhang $Y, W u Y$. The prevalence of depressive symptoms among the older in China: a meta-analysis. Int J Geriatr Psychiatry. 2012;27:900-6.

6. Kok RM, Reynolds CF 3rd. Management of depression in older adults: a review. JAMA. 2017:317:2114-22.

7. Bowling CB, Sharma P, Fox CS, O'Hare AM, Muntner P. Prevalence of reduced estimated glomerular filtration rate among the oldest old from 1988-1994 through 2005-2010. JAMA. 2013;310:1284-6.

8. Coresh J, Selvin E, Stevens LA, Manzi J, Kusek JW, Eggers P, Van Lente F, Levey AS. Prevalence of chronic kidney disease in the United States. JAMA. 2007;298:2038-47.

9. Liu Q, Li YX, Hu ZH, Jiang XY, Li SJ, Wang XF. Reduced estimated glomerular filtration rate is associated with depressive symptoms in elder Chinese: a population-based cross-sectional study. Neurosci Lett. 2017;666:127-32.

10. Feng $L$, Yap KB, Ng TP. Depressive symptoms in older adults with chronic kidney disease: mortality, quality of life outcomes, and correlates. Am J Geriatr Psychiatry. 2013;21:570-9.

11. Campbell KH, Huang ES, Dale W, Parker MM, John PM, Young BA, Moffet $\mathrm{HH}$, Laiteerapong N, Karter AJ. Association between estimated GFR, healthrelated quality of life, and depression among older adults with diabetes: the diabetes and aging study. Am J Kidney Dis. 2013;62:541-8.

12. Liang Y, Yan Z, Sun B, Cai C, Jiang H, Song A, Qiu C. Cardiovascular risk factor profiles for peripheral artery disease and carotid atherosclerosis among Chinese older people: a population-based study. PLoS One. 2014:9:e85927.

13. Wang R, Yan Z, Liang Y, Tan EC, Cai C, Jiang H, Song A, Qiu C. Prevalence and patterns of chronic disease pairs and multimorbidity among older Chinese adults living in a rural area. PLoS One. 2015;10:e0138521.

14. Song A, Liang Y, Yan Z, Sun B, Cai C, Jiang H, Qiu C. Highly prevalent and poorly controlled cardiovascular risk factors among Chinese elderly people living in the rural community. Eur J Prev Cardiol. 2014:21:1267-74.

15. Yan Z, Liang Y, Shi J, Cai C, Jiang H, Song A, Qiu C. Carotid stenosis and cognitive impairment amongst older Chinese adults living in a rural area: a population-based study. Eur J Neurol. 2016:23:201-4.

16. Cui GH, Yao YH, Xu RF, Tang HD, Jiang GX, Wang Y, Wang G, Chen SD, Cheng Q. Cognitive impairment using education-based cutoff points for CMMSE scores in elderly Chinese people of agricultural and rural Shanghai China. Acta Neurol Scand. 2011:124:361-7.

17. Welmer AK, Liang Y, Angleman S, Santoni G, Yan Z, Cai C, Qiu C. Vascular risk factor burden, atherosclerosis, and functional dependence in old age: a population-based study. Int J Behav Med. 2014;21:597-604. 
18. Inker $L A$, Schmid $C H$, Tighiouart $H$, Eckfeldt JH, Feldman HI, Greene T, Kusek JW, Manzi J, Van Lente F, Zhang YL, et al. Estimating glomerular filtration rate from serum creatinine and cystatin C. N Engl J Med. 2012;367:20-9.

19. Yin Z, Yan Z, Liang Y, Jiang H, Cai C, Song A, Feng L, Qiu C. Interactive effects of diabetes and impaired kidney function on cognitive performance in old age: a population-based study. BMC Geriatr. 2016;16:7.

20. Feng L, Yan Z, Sun B, Cai C, Jiang H, Kua EH, Ng TP, Qiu C. Tea consumption and depressive symptoms in older people in rural China. J Am Geriatr Soc. 2013;61:1943-7.

21. Nyunt MS, Fones C, Niti M, Ng TP. Criterion-based validity and reliability of the geriatric depression screening scale (GDS-15) in a large validation sample of community-living Asian older adults. Aging Ment Health. 2009;13:376-82.

22. Marc LG, Raue PJ, Bruce ML. Screening performance of the 15 -item geriatric depression scale in a diverse elderly home care population. Am J Geriatr Psychiatry. 2008:16:914-21.

23. Yaffe K, Lindquist K, Shlipak MG, Simonsick E, Fried L, Rosano C, Satterfield S, Atkinson $\mathrm{H}$, Windham BG, Kurella-Tamura M. Cystatin $\mathrm{C}$ as a marker of cognitive function in elders: findings from the health $A B C$ study. Ann Neurol. 2008;63:798-802.

24. Martens RJH, Kooman JP, Stehouwer CDA, Dagnelie PC, van der Kallen CJH, Kroon AA, Leunissen KML, van der Sande FM, Schaper NC, Sep SJS, et al. Albuminuria is associated with a higher prevalence of depression in a population-based cohort study: the Maastricht study. Nephrol Dial Transplant. 2018;33:128-38.

25. Minev E, Unruh M, Shlipak MG, Simsonick E, Yaffe K, Leak TS, Newman AB, Fried LF, Health ABC Study. Association of cystatin $C$ and depression in healthy elders: the health, aging and body composition study. Nephron Clin Pract. 2010;116:c241-6.

26. Onopiuk A, Tokarzewicz A, Gorodkiewicz E. Cystatin C: a kidney function biomarker. Adv Clin Chem. 2015;68:57-69.

27. Rule AD, Rodeheffer RJ, Larson TS, Burnett JC Jr, Cosio FG, Turner ST, Jacobsen SJ. Limitations of estimating glomerular filtration rate from serum creatinine in the general population. Mayo Clin Proc. 2006;81:1427-34.

28. Akoudad S, Sedaghat S, Hofman A, Koudstaal PJ, van der Lugt A, Ikram MA, Vernooij MW. Kidney function and cerebral small vessel disease in the general population. Int J Stroke. 2015;10:603-8.

29. Wada M, Nagasawa H, Kawanami T, Kurita K, Daimon M, Kubota I, Kayama T, Kato T. Cystatin $C$ as an index of cerebral small vessel disease: results of a cross-sectional study in community-based Japanese elderly. Eur J Neurol. 2010;17:383-90

30. van Agtmaal MJM, Houben AJHM, Pouwer F, Stehouwer CDA, Schram MT. Association of microvascular dysfunction with late-life depression: a systematic review and meta-analysis. JAMA Psychiatry. 2017;74:729-39.

31. Aizenstein HJ, Baskys A, Boldrini M, Butters MA, Diniz BS, Jaiswal MK Jellinger KA, Kruglov LS, Meshandin IA, Mijajlovic MD, et al. Vascular depression consensus report - a critical update. BMC Med. 2016:14:161.

32. Arpegård J, Ostergren J, de Faire U, Hansson LO, Svensson P. Cystatin C--a marker of peripheral atherosclerotic disease? Atherosclerosis. 2008;199:397-401.

33. Yalcin S, Ulas T, Eren MA, Aydogan H, Camuzcuoglu A, Kucuk A, Yuce HH, Demir ME, Vural M, Aksoy N. Relationship between oxidative stress parameters and cystatin C levels in patients with severe preeclampsia. Medicina (Kaunas). 2013;49:118-23.

34. van Dooren FE, Schram MT, Schalkwijk CG, Stehouwer CD, Henry RM, Dagnelie PC, Schaper NC, van der Kallen CJ, Koster A, Sep SJ, et al. Associations of low grade inflammation and endothelial dysfunction with depression - the Maastricht study. Brain Behav Immun. 2016;56:390-6.

35. Keller C, Katz R, Cushman M, Fried LF, Shlipak M. Association of kidney function with inflammatory and procoagulant markers in a diverse cohort: a cross-sectional analysis from the multi-ethnic study of atherosclerosis (MESA). BMC Nephrol. 2008;9:9.

36. Carlsson AC, Nordquist L, Larsson TE, Carrero J, Larsson A, Lind L, Ärnlöv J. Soluble tumor necrosis factor receptor 1 is associated with glomerular filtration rate progression and incidence of chronic kidney disease in two communitybased cohorts of elderly individuals. Cardiorenal Med. 2015;5:278-88.

37. Smith KJ, Au B, Ollis L, Schmitz N. The association between C-reactive protein, Interleukin-6 and depression among older adults in the community: a systematic review and meta-analysis. Exp Gerontol. 2018;102:109-32.

Ready to submit your research? Choose BMC and benefit from:

- fast, convenient online submission

- thorough peer review by experienced researchers in your field

- rapid publication on acceptance

- support for research data, including large and complex data types

- gold Open Access which fosters wider collaboration and increased citations

- maximum visibility for your research: over $100 \mathrm{M}$ website views per year

At BMC, research is always in progress.

Learn more biomedcentral.com/submissions 